\title{
Quiz ClassRoom Libras: Um jogo didático multidisciplinar para alunos surdos da Educação de Jovens e Adultos
}

\author{
Welsing M. Pereira ${ }^{1}$, Emanuele Nunes de L. F. Jorge ${ }^{1}$, André G. Valente ${ }^{1}$, \\ Fernanda P. S. Gouveia ${ }^{1}$, Ana Caroline C. M. Amaro ${ }^{1}$, Rafael de Oliveira Costa ${ }^{1}$ \\ ${ }^{1}$ Instituto Federal do Rio de Janeiro (IFRJ) \\ Av. República do Paraguai, 120 - Duque de Caxias - RJ - Brazil \\ welsing.pereira, emanuele.jorge, andre.valente@ifrj.edu.br \\ fernanda.gouveia, ana.amaro,rafael.oliveira@ifrj.edu.br
}

\begin{abstract}
Resumo. Muitos estudos no campo da educação abordam a vivência do lúdico como central para a construção do conhecimento, apesar de tradicionalmente lhe ser concedido um lugar secundário em favor da racionalidade [Santin 1994]. Em nossa experiência, consideramos a ludicidade a partir dos jogos como potente instrumento para produção do conhecimento na Educação de Jovens e Adultos (EJA), principalmente na realidade de seus sujeitos surdos no Proeja. Por isso, nossa proposta apresenta o desenvolvimento de um jogo didático que funcione como um agente facilitador na educação de surdos, possibilitando a inserção de uma atividade lúdica no processo de ensinoaprendizagem.A ideia surgiu a partir de um projeto de extensão, e posteriormente, um projeto de pesquisa ativo no Instituto Federal do Rio de Janeiro, no qual foram criados dois produtos educacionais, o Quiz Matemático e o Quiz ClassRoom, permitindo uma evolução que o torna multidisciplinar e inclusivo ao surdo, o Quiz ClassRoom Libras. Em etapa anterior da pesquisa, registramos críticas dos discentes surdos aos limites do quiz, o que nos motivou a pensar em alternativas alinhadas à educação inclusiva. Dessa forma, narramos este movimento de aproximação às demandas dos sujeitos surdos, mesmo convivendo num cenário severo de contingenciamento de recursos das instituições públicas federais, o qual inviabiliza grande parte destas ações. Isto posto, relatamos uma experiência em construção que vem caminhando para que estudantes surdos do Curso Técnico em Manutenção e Suporte em Informática (MSI), do Instituto Federal do Rio de Janeiro (IFRJ), campus Duque de Caxias, possam ampliar seus conhecimentos nos diferentes temas abordados no quiz, permitam maior apropriação de metodologias lúdicas pelos docentes atuantes na EJA e estimulem outras práticas inclusivas.
\end{abstract}

\begin{abstract}
Many studies in the field of education address the experience of the ludic as a central point for knowledge construction, although it has traditionally been given a secondary place in favor of rationality [Santin 1994]. Nevertheless, in our experience, we consider the ludic side of games as a powerful tool for knowledge production in Youth and Adult Education (EJA), especially in the reality of their deaf subjects in Proeja. Therefore, our proposal presents a didactic game that works as a facilitating agent in deaf education, allowing the insertion of a ludic activity in the teaching-learning process. The idea came
\end{abstract}


VIII Congresso Brasileiro de Informática na Educação (CBIE 2019)

Anais dos Workshops do VIII Congresso Brasileiro de Informática na Educação (WCBIE 2019)

from an extension project, that became an active research project at the Federal Institute of Rio de Janeiro, in which two educational products were created, the Quiz Matemático and the Quiz ClassRoom, allowing an evolution that makes it multidisciplinary and inclusive of the deaf, the Quiz ClassRoom Libras. In an earlier stage of the research, we recorded criticism from deaf students to the limits of the quiz, which motivated us to think of alternatives aligned to inclusive education. Thus, we narrate this movement of approximation to the demands of deaf subjects, even living in a severe scenario of resource contingency of federal public institutions, which makes most of these actions unfeasible. Thus, we report an experience in construction that has been moving so that deaf students of the Technical Course in Computer Maintenance and Support (MSI), Federal Institute of Rio de Janeiro (IFRJ) in Duque de Caxias, can broaden their knowledge in different topics covered in the quiz allowing greater appropriation of ludic methodologies by teachers working in the EJA and stimulate other inclusive practices.

\section{Introdução}

Desde 2006, o Programa Nacional de Integração da Educação Profissional com a Educação Básica na Modalidade de Educação de Jovens e Adultos (PROEJA) se apresenta na realidade das instituições federais de educação técnico-profissional. Tal programa foi instituído pelo Decreto no 5.840 de 13 de julho de 2006 e declara que a oferta do Programa se dará de forma compulsória à Rede Federal, garantindo que $10 \%$ do total de vagas ofertadas por suas instituições se destinem ao mesmo. Tal compulsoriedade promoveu um avanço significativo na presença desta modalidade em uma rede estabelecida de educação profissional, mesmo que ela detenha pouca expertise na modalidade de Educação de Jovens e Adultos (EJA), principalmente em sua experiência integrada. Acredita-se que, sem a força da legislação, a permanência de pouco mais de 10 anos do PROEJA na Rede Federal possivelmente não se sustentaria, especialmente pelas relações de poder e interesse que incidem sobre a educação dos trabalhadores [Gouveia 2018, de Abreu Júnior 2007].

No contexto da educação inclusiva, potencializam-se os desafios postos à EJA, que possui uma realidade histórica descontínua, fragmentada e apartada de políticas integradoras da educação básica [Gouveia 2019]. No Campus Duque de Caxias, a inserção deste público iniciou após a Lei de Cotas de 2016 ( ${ }^{o}$ 13.409/2016). Desde então, discentes surdos, paulatinamente, ingressam no Curso técnico em MSI integrado ao ensino médio na modalidade EJA. Tal cenário provocou a mobilização da direção escolar, professores, tradutores intérpretes de Libras e equipe pedagógica na busca da ampliação de recursos pedagógicos e humanos para a inclusão dos discentes surdos.

Os alunos surdos têm sido alvo de muitas discussões na Instituição, e sua incompreensão e polêmica constituem, nos dias de hoje, um grande desafio para a sociedade e para a educação. Ao refletir sobre as metodologias pedagógicas aplicadas em sala de aula para auxiliar no processo de ensino-aprendizagem inclusivo, observa-se que as Tecnologias de Informação e Comunicação - TICs ocupam um papel importante no processo educacional do aluno surdo. Nesse sentido, consideramos que uma das TICs que possibilitam a apropriação do conhecimento de uma forma significativa são os jogos didáticos. Jogos são instrumentos pedagógicos riquíssimos para aprendizagem e exploração de conteúdos 
VIII Congresso Brasileiro de Informática na Educação (CBIE 2019)

Anais dos Workshops do VIII Congresso Brasileiro de Informática na Educação (WCBIE 2019)

que podem ser usados tanto em sala de aula, como também em outros espaços não formais, saber trabalhar com eles poderá fazer toda diferença, pois será estimulado a curiosidade e interesse conforme preconiza [Piaget 2003].

Nesta perspectiva, o jogo didático constitui-se como uma atividade lúdica que funciona como um facilitador para o professor transmitir conhecimentos de uma forma divertida e interativa para que os alunos surdos se apropriem de conceitos resultante de um aprendizado com significado.

Diante do exposto, desenvolvemos um jogo didático que funcione como um agente facilitador na educação de surdos, possibilitando a inserção de uma atividade lúdica no processo de ensino-aprendizagem destes alunos no Curso Técnico em MSI integrado ao ensino médio na modalidade EJA e apresentamos a experiência, ainda em desenvolvimento, que objetiva contribuir para a aprendizagem dos mesmos, compreendendo suas trajetórias e construindo ferramentas para que os educandos surdos da EJA superem os desafios, tendo em vista, o fortalecimento destes discentes na instituição, visto que novas metodologias de ensino e abordagens voltadas para suas especificidades podem estimular a permanência dos mesmos.

Mais adiante, o trabalho está organizado da seguinte forma: a Seção 2 apresenta os desafios na escolarização dos Surdos. A Seção 3 apresenta o Quiz ClassRoom Libras, onde mostramos o desenvolvimento do jogo. Na seção 4, mostramos o relato da experiência. Na seção 5 apresentamos conclusões e trabalhos futuros.

\section{Os Desafios na escolarização dos Surdos}

O alarmante fato de que a educação de sujeitos surdos apresenta índices de aspectos acadêmicos muito aquém dos apresentados pela educação de alunos ouvintes, apesar de suas capacidades cognitivas serem idênticas [Lacerda 2006], explicita de forma transparente a inadequação do atual sistema brasileiro de ensino quanto a esta questão. Nas últimas décadas diversas ações têm sido tomadas para a mudança deste cenário, mas ainda existem diversas barreiras a serem ultrapassadas. Neste período houve uma mudança nos paradigmas relacionados a educação de surdos, as escolas especiais perderam uma posição central e programas de incentivo a inclusão de surdos em escolas regulares se tornaram predominantes. Este movimento, apesar de ser positivo em vários aspectos, apresenta escassez de recursos, estruturas e formação de profissionais nas escolas brasileiras.

Em um cenário onde é possível a escola receber, em suas turmas regulares, alunos com diversas necessidades específicas simultaneamente, um efetivo preparo prévio de suas estruturas físicas e de seus recursos humanos se faz necessário, seja em escolas públicas ou privadas de todos os seguimentos, o que na realidade, é comumente negligenciado [Ribeiro 2004]. Em particular, no caso do sujeito surdo, para um efetivo processo de aprendizagem, é fundamental o uso e o reconhecimento da Libras na preparação das aulas, assim como na presença do intérprete de Libras qualificado. No entanto, existem poucas pessoas com formação adequada para atuar como professor bilíngue (Libras e Português) e intérprete de Libras em escolas regulares [Lacerda 2006], apesar do aumento de oferta de cursos de formação para estes profissionais. O que ocorre é uma grande concentração desses profissionais nas grandes cidades e portanto, não é acessível a todos, pois em cidades do interior do Brasil, pouquíssimas são as pessoas com esta formação específica 
VIII Congresso Brasileiro de Informática na Educação (CBIE 2019)

Anais dos Workshops do VIII Congresso Brasileiro de Informática na Educação (WCBIE 2019)

e os alunos surdos destas regiões são em diversas situações impedidos de ter acesso aos conteúdos acadêmicos.

Ao contrário da maioria das crianças que aprendem sua língua materna em casa, as crianças surdas de pais ouvintes dependem da ação mediadora da escola para aprenderem a língua de sinais [Fernandes 2009]. Por conta disto, a escola precisa, em alguns casos, ampliar sua finalidade principal de garantir acesso à educação formal, estendendoa para a educação linguística das crianças surdas, e em muitas situações substituindo a família ouvinte na promoção de um ambiente favorável à apropriação da língua de sinais pelo aluno surdo e também, em diversas situações, até mesmo fornecendo ensino da Libras aos familiares ouvintes. Estas questões reforçam ainda mais a necessidade de uma escola efetivamente preparada para receber, acolher e formar sujeitos surdos, com adequado suporte e este aluno em diversos aspectos, inclusive incluindo assistência a seus familiares.

A partir das políticas públicas para efetivação da educação de surdos preconizados pelo Decreto $n^{0}$. 3.298/1999, a Lei $n^{0}$. 7.853/1989; a Lei ${ }^{\circ}$. 9.394/1995; a Lei $n^{0}$ 13.146/2015; a regulamentação e oficialização da Língua Brasileira de Sinais pela Lei $\mathrm{n}^{\mathrm{o}} 10.436 / 02$ e o Decreto $\mathrm{n}^{\mathrm{o}}$. 5.626/05; e o Estatuto da Pessoa com Deficiência, Lei $\mathrm{n}^{\mathrm{o}}$ $13.146 / 2015$ promovem tanto a integração como sugerem a criação e o aprimoramento de artefatos pedagógicos para a inclusão das pessoas surdas nas instituições de ensino.

No artigo $14^{\circ}$ da Lei $n^{\circ} 13.146 / 2015$ solicita-se às instituições de ensino garantir de forma obrigatória, o acesso à comunicação, informação e educação nos processos seletivos, nas atividades e nos conteúdos curriculares em todos os níveis, etapas e modalidades de educação.

Dentre tanto fatores, a comunidade surda vive o dilema de sentir-se estrangeira em seu próprio país, pois a barreira linguística restringe o acesso à informação, cultura, comunicação e outros. Para minimizar esses danos, em âmbito educacional, torna-se necessário a conscientização e o posicionamento político-pedagógico de todos os educadores na aceitação e no uso da LIBRAS durante todo o processo de ensino-aprendizagem.

Especificamente discentes surdos e ouvintes da EJA são alvos da negligência nos sistemas de ensino público. Segundo [Arroyo 2006], as marcas das desigualdades impossibilitam a população pobre e/ou trabalhadora de frequentar a escola, mas alguns fatores justificam a superação dessas barreiras sociais, proporcionando o retorno às salas de aula, como a qualificação para o mercado de trabalho, o acompanhamento dos filhos nos estudos, interesses religiosos e emancipação humana como sujeitos históricos e críticos, desmistificando a ideia de cidadão como capital humano. Para o autor, a educação como direito está entrelaçado aos direitos humanos básicos.

\section{O Quiz ClassRoom Libras}

O Quiz ClassRoom Libras é um software educacional de perguntas e respostas em que os professores atuam como administradores na elaboração de grupos de questões objetivas e os alunos atuam como jogadores respondendo as perguntas. O jogo está em constante atualização e é uma evolução do Quiz Matemático e do Quiz ClassRoom para ser usado por alunos surdos. Dessa forma, tornando-se multidisciplinar e inclusivo. Outras características do jogo é que ele é ecológico e econômico, pois os exercícios e provas são 
VIII Congresso Brasileiro de Informática na Educação (CBIE 2019)

Anais dos Workshops do VIII Congresso Brasileiro de Informática na Educação (WCBIE 2019)

realizados de forma online sem a necessidade do uso de materiais de expediente como papel e equipamento de impressão. O objetivo do jogo é proporcionar o contato com novas formas de aprendizagem, estimulando os estudantes a responder as questões, esclarecer possíveis dúvidas e reconhecer seu aprendizado em sua língua a partir dos resultados apresentados ao longo desse processo.

O Jogo está disponibilizado para smartphones com o sistema operacional Android através do serviço de distribuição digital de aplicativos Google Play e também através do link http://quizlibras.proetec.com.br. Durante o seu desenvolvimento foi utilizada a plataforma Unity Personal com scripts na linguagem C\# e acesso ao banco de dados MySQL utilizando o phpMyAdmin como interface web. O aplicativo possui interface simples, mas design atraente. Para jogá-lo, é necessário efetuar um cadastro no próprio aplicativo utilizando uma chave do jogo. O docente elabora um conjunto de perguntas e respostas sobre um assunto específico com vídeos, imagens e textos sob uma chave com 8 dígitos que deve ser repassada aos discentes. A configuração do jogo permite estabelecer um período de validade da chave, possibilitando ao docente o planejamento das atividades pedagógicas visando todo o processo de avaliação da aprendizagem.

O jogo trata a inclusão do aluno surdo onde para cada pergunta ou resposta é possível associar um vídeo com interpretação em libras e uma imagem relacionada à cada questão. Estes recursos, preveem uma maior independência do aluno surdo durante sua atuação no jogo. Assim, como toda ferramenta de apoio à aprendizagem, é necessário que o professor elabore estratégias para que se obtenha resultados satisfatórios à aprendizagem.

A figura 1 apresenta 8 telas do jogo, a saber: (i) Menu do Usuário; (ii) Menu do jogo, com uma chave funcional definida pelo número: "12381311"; (iii) Questão 4 do quiz; (iv) Resposta Certa; (v) Questão 7 do quiz; (vi) Vídeo em libras associado à pergunta 7; (vii) Resumo do Jogo e (viii) Tela de Saída do Jogo. A tela Menu do Usuário permite ao usuário efetuar a troca da senha, tirar e trocar sua foto, visualizar informações sobre o jogo, acessar o jogo com novo usuário e sair do jogo. A tela Menu do Jogo permite ao usuário visualizar e imprimir as suas provas, visualizar dados do último quiz que foi jogado e acessar o jogo a partir da digitação da chave de 8 dígitos As telas iii, v e vi contém as perguntas e as alternativas de resposta do jogo, tais alternativas são listadas de A a D em símbolos de libras e ao lado de cada pergunta ou alternativa, o jogador tem um botão com o símbolo em libras que possibilita o jogador visualizar um vídeo em libras quando pressionado. Quando o botão possui um x branco dentro de um círculo vermelho a pergunta ou a alternativa não tem vídeo em libras associado a ela ainda A tela Resposta certa permite ao usuário visualizar se acertou a questão. A tela Resumo do jogo apresenta ao jogador um resumo com a sua nota, seus acertos e seus erros no quiz jogado. A tela Tela de saída do jogo é apresentada sempre que um jogador pressiona o botão sair do jogo.

\section{Relato de Experiência}

A experiência dos quizzes nasce da necessidade de ampliar as oportunidades de aprendizagem do sujeito jovem e adulto na realidade empírica do Campus Duque de Caxias. Especificamente no campo da matemática os índices de retenção se apresentavam bem altos, motivando o conjunto docente a pensar em estratégias integradoras e promotoras de 
VIII Congresso Brasileiro de Informática na Educação (CBIE 2019)

Anais dos Workshops do VIII Congresso Brasileiro de Informática na Educação (WCBIE 2019)

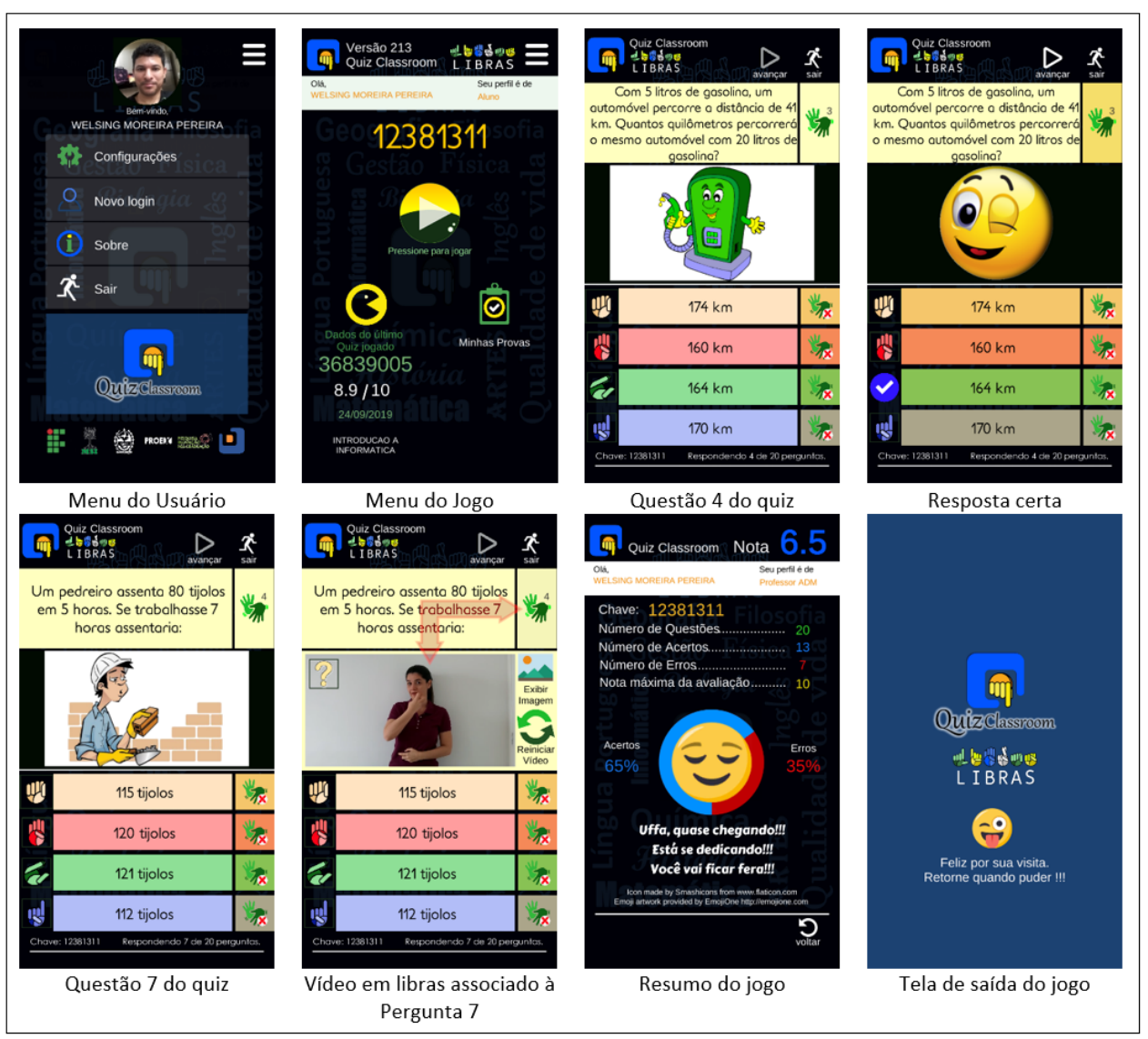

Figura 1. Telas do jogo Quiz ClassRoom Libras.

conhecimento.

Em relato de pesquisa anterior [Valente et al. 2019] observaram que os discentes reconheceram a potência da ferramenta do quiz, indicando que a mesma fortaleceu seus conhecimentos, ajudou a consolidar os conhecimentos desenvolvidos em sala de aula, facilitou a aprendizagem e permitiu que os mesmos busquem em seus desacertos novas respostas. Construiu novos conhecimentos, no seu ritmo e no seu tempo, visto que poderiam acessar pelo celular, lhes concedendo autonomia sobre a melhor hora e lugar para acessar a plataforma. Por críticas, a metodologia foi analisada por alguns discentes como limitada em seu sentido restrito à ideia avaliativa, podendo recorrer a outros objetivos e formatos.

Nesta mesma pesquisa [Valente et al. 2019] também verificaram que o desafio dos pesquisadores se dava mais diretamente nas demandas dos sujeitos surdos que alegavam que as perguntas não eram claras e que, por não dominarem plenamente o português, solicitaram a inclusão da linguagem dos sinais. Este é o passo que a experiência aqui relatado vem dando, construindo questões associadas aos traduzidos pelos intérpretes de Libras o que, vale ressaltar, tem se desenvolvido de forma precária e bem lenta em função do processo severo de contingenciamento de recursos nas escolas públicas federais no ano de 2019.

Nossos sujeitos surdos da EJA nos desafia a pensar novas metodologias inclusivas, o que nos exige mais formação e conhecimento para atender tal demanda. Mesmo com os 
VIII Congresso Brasileiro de Informática na Educação (CBIE 2019)

Anais dos Workshops do VIII Congresso Brasileiro de Informática na Educação (WCBIE 2019)

limites desta ferramenta em seu objetivo avaliativo, acreditamos que a adaptação do quiz à necessidade destes sujeitos nos imputa a ampliar nossa abordagem pedagógica, considerar as situações da realidade social e a construir, no processo que está em andamento, conteúdos comprometidos com a educação inclusiva.

\section{Conclusão e Trabalhos Futuros}

Este trabalho apresenta um relato de experiência que expressa a construção do conhecimento e formação continuada de profissionais atentos às demandas da população jovem e adulta, em particular de sujeitos surdos. Apresentou-se um produto desenvolvido com diversas ferramentas das mais modernas e funcionais para a criação de aplicações mobile. Confeccionado pelos docentes da EJA com a colaboração da tradutora e intérprete de libras do IFRJ, Campus Duque de Caxias. Este projeto de âmbito de pesquisas fomentadas pela instituição, propõe a utilização deste produto por alunos surdos e ouvintes do Curso de Manutenção e Suporte a Informática, integrado ao ensino médio, do Campus Duque de Caxias.

Observou-se que mesmo com diversos limites a serem superados, a experiência proposta se apresenta como uma oportunidade de construção do pensamento e conhecimento coletivo a partir de sujeitos pertencentes à EJA, seja na condição de discentes ou de docentes, de surdos ou de ouvintes. Uma oportunidade também de dar visibilidade e protagonismo à modalidade e ao PROEJA em si, principalmente num cenário que avança na direção de seu apagamento.

Pode-se citar como desafiador a dificuldade na produção dos vídeos em libras com a tradução das perguntas e das respostas nos quizzes. Em um cenário de precarização da educação pública, os profissionais intérpretes de Libras são poucos e nem sempre tem disponibilidade para produção deste material. No contexto da experiência relatada neste trabalho, o Campus Duque da Caxias do IFRJ, possui apenas uma servidora tradutora e intérprete de Libras, mesmo o Campus possuindo, no segundo semestre de 2019, dois alunos surdos matriculados em turmas diferentes no turno noturno.

A experiência relatada explicita a importância de práticas pedagógicas que autonomizem os sujeitos atendidos, orientadas pelo sentido da garantia do direito à educação, inspiradas pelos objetivos de sua permanência e êxito. A partir destes dados pode-se entender que há um longo caminho a ser trilhado na direção da formulação de diretrizes e práticas pedagógicas que promovam adequadamente uma efetiva inclusão. Ações de curto, médio e longo prazo devem ser construídas para estruturar o ensino de acordo com as demandas do público surdo na instituição, principalmente no processo de ensinoaprendizagem.

Assim, pretende-se continuar o desenvolvimento do Quiz ClassRoom Libras como ferramenta didática, identificando e construindo funcionalidades para potencializar seu uso por professores e alunos, surdos e ouvintes. Pretende-se também intensificar a pesquisa multidisciplinar sobre o uso do aplicativo, elaborando metodologias, nas diversas disciplinas que compõe o currículo escolar, analisando e publicando os êxitos e os desafios. Neste sentido, reconhecer os limites e as potencialidades das ferramentas pedagógicas é fundamental para que seja possível repensar abordagens e promover a desenvolvimento de novas propostas que se aproximem da perspectiva do currículo integrado proposto na concepção norteadora do Proeja, assim como permitir que sejam consolidadas 
VIII Congresso Brasileiro de Informática na Educação (CBIE 2019)

Anais dos Workshops do VIII Congresso Brasileiro de Informática na Educação (WCBIE 2019)

práticas que produzam conhecimento, garantam a permanência e o êxito dos educandos.

\section{Referências}

Arroyo, M. (2006). Formar educadoras e educadores de jovens e adultos. Formação de educadores de jovens e adultos. Belo Horizonte: Autentica, pages 17-32.

de Abreu Júnior, J. M. (2007). Os processos de acesso e permanência nos cursos PROEJA do IFRJ: entre percalços, demandas e potencialidades. $\mathrm{PhD}$ thesis, Universidade do Estado do Rio de Janeiro -Centro de Educação e Humanidades - Faculdade de Educação.

Fernandes, Sueli e Moreira, L. C. (2009). Desdobramentos politico-pedagógicos do bilinguismo para surdos: reflexões e encaminhamentos. Revista Educação Especial, 22(34).

Gouveia, F. P. S. (2018). Proeja e mundo do trabalho: inserção, reinserção e horizonte precário. PhD thesis, Programa de Pós-Graduação em Políticas Públicas e Formação Humana. Universidade do Estado do Rio de Janeiro, Rio de Janeiro.

Gouveia, F. P. S. (2019). Faces da precarização do mundo do trabalho e a juventude sobrante. Estudos IAT, 4(1):124-137.

Lacerda, C. B. F. (2006). A inclusão escolar de alunos surdos: o que dizem alunos, professores e intérpretes sobre esta experiência. Cad. Cedes, 26(69):163-184.

Piaget, J. (2003). Seis estudos de psicologia. 24. Edição Forense-Universitária ISBN 8521802463, Rio de Janeiro.

Ribeiro, S. L. (2004). Espaço escolar: um elemento (in) visível no currículo. Sitientibus, Feira de Santana, 31:103-18.

Santin, S. (1994). Educação física: da alegria do lúdico à oppressão do rendimento. Edições EST/ESEF-UFRGS.

Valente, A. G., Pereira, W. M., Gouveia, F. P. S., and Jorge, E. N. L. F. (2019). Uma proposta de metodologia de ensino da matemática no proeja por meio de quizzes. Anais do XIII ENEM - Encontro Nacional de Educação Matemática, Cuiabá MT. 